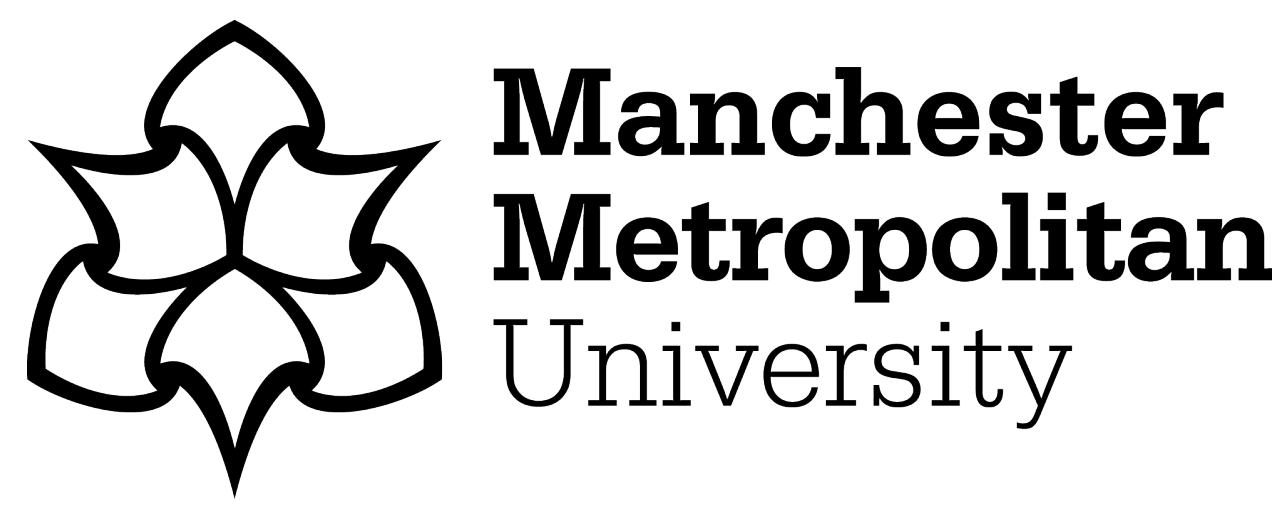

Bell, HM (2016) Teacher knowledge and beliefs about grammar: a case study of an English primary school. English in Education, 50 (2). pp. 148-163. ISSN 0425-0494

Downloaded from: https://e-space.mmu.ac.uk/613342/

Version: Accepted Version

Publisher: Wiley

DOI: https://doi.org/10.1111/eie.12100

Please cite the published version 


\section{Teacher knowledge and beliefs about grammar: a case study of an English primary school}

\section{Introduction and background}

This paper is a case study of developing teacher attitudes, beliefs and content knowledge at one primary school in the North-West of England. It deals with the new spelling, punctuation and grammar ( $\mathrm{SPaG}$ ) elements of the National Curriculum, focusing particularly on grammatical terms and concepts. It uses data collected over 10 months from June 2014 to March 2015, including surveys, interviews and comments made during post-observation discussions and SPaG CPD sessions.

Patience Holt Primary ${ }^{1}$ is a medium-sized school in bright, modern premises in urban North-West England. A recent OFSTED report classifies it as 'good' in all categories, comments positively on the commitment and enthusiasm of the staff, and notes sustained successful efforts to improve. Almost all the children have English as an additional language (EAL). 18 out of 19 teaching staff have English as a first language (L1), but many classroom assistants and a few teachers have second languages in common with the children's own first or second languages.

The National Curriculum 2014 (henceforth NC2014) introduced substantial changes to the types of knowledge about language (KAL) and knowledge about grammar (KAG) English schools are required to teach. It specifies terms to be taught in each year, including around 30 grammar terms supplemented by a Glossary which incorporates around another 20 terms. The new content is formally examined in the SPaG test' in Year 6, and there are plans to introduce a test at Y2 (STFA, 2015). This is a significant change from much of the mid-late $20^{\text {th }}$ century when grammar was hardly taught (Crystal 2006), and possibly the most significant aspect of this is the terminology itself: an extensive list of grammar terms has been enshrined in statute, and for this reason knowing more about what teachers know is an urgent issue. In fact the move towards increased grammar teaching has been gaining momentum for a number of years (Paterson 2010), for example through the National Literacy Strategies of the late $20^{\text {th }}$ and early $21^{\text {st }}$ centuries; in its current incarnation, however, NC2014 still represents a considerable increase in the specificity and quantity of grammatical terminology. A full discussion of this movement to embed more formal grammar 
knowledge in primary school is not necessary here, but similar changes have taken place across much of the Anglophone world (cf. ACARA 2012; Ministry of Education 2007).

These changes have given rise to research and comment on a range of associated issues. One strand concerns the accuracy and nature of the curricular documentation (Sealey 1999; Cajkler 2004; Clark 2010; Bell 2014). Another focuses on the effect of instruction on writing (e.g. Myhill, Jones, Lines and Watson 2012; Myhill, Jones and Watson 2013); this has been accompanied by several recent books for teachers dealing with teaching grammar effectively (e.g. Waugh et al. 2013; Reedy and Bearne 2013). Considerable research focusses on teachers' grammar knowledge and confidence, and teacher beliefs and attitudes about grammar and grammar teaching. In broad agreement with earlier studies, Williamson and Hardman's 1995 study of 99 primary trainees' KAG reports significant weaknesses and misunderstandings, and notes ruefully that without "significant input during their initial training, and through inservice courses, bad [teaching] practice will continue" (1995: 129). In a larger study of primary trainees across four years, Cajkler and Hislam report considerable variation in the ability to identify word classes, and continuing confusion and anxiety. Noting that merely "challenging trainee teachers through audits and skills tests to redress a deficit that has grown for decades is unfair and unrealistic" (2002: 176), they make a number of perceptive recommendations for research and for better, longer-term instruction for trainees. Another large-scale study of trainee teachers finds that “confidence markedly outstrip[ped]...knowledge" (Sangster, Anderson and O'Hara, 2013: 310) - trainees believed they knew more than they did. While all three papers imply unresolved issues in reliably auditing grammatical knowledge, taken in the round all suggest considerable scope for improvement. They are also studies of trainees rather than practising, qualified teachers, as are a number of smaller scale studies (e.g. Harper and Rennie, 2009). Research in Australia (Jones and Chen 2012) and New Zealand (Jeurissen 2012) has found similar results. Jeurrisen reports that primary teachers' KAG was "generally poor" (p.306) but improved somewhat with training. Jones and Chen (2012) suggest even the most experienced teachers have gaps in their knowledge. Inadequate subject knowledge "can have untold effects on teachers' confidence" (Leech, Williams and Andrews 2002: 646), and Bibby's (2002) use of the 
notion of 'shame' in describing this relationship gives a powerful insight into how fraught it can be.

The complex relationship between what teachers believe about grammar and how they teach it has been widely reported (e.g. Phipps and Borg 2009). At the start of the current re-evaluation of grammar in the curriculum, the QCA (1998) reported negative beliefs about the value of grammar teaching among school teachers, a finding upheld by later studies (Watson 2012 and 2015).

\section{The context of this study}

The origins of this report lie in in-service grammar training delivered by the author in Patience Holt at the request of the senior leadership team (SLT). To improve staff knowledge of the terminology of NC2014, the school originally requested a 'grammar audit' of all staff followed by three 1-hour input sessions. The author's involvement has since taken a number of forms, shaped by changing requirements.

In June 2014, staff completed a survey with two sections. The first collected information about knowledge of languages and previous study of grammar, and allowed them to self-report confidence in their knowledge of grammatical terminology; the second assessed their attitudes to and beliefs about teaching and learning grammar terms. 19 teaching staff and 21 teaching support staff (henceforth TS and TSS respectively) completed the survey.

The first 1-hour session was delivered to both TS and TSS, but subsequent sessions were for teachers only. These were supplemented by smaller sessions with teachers from particular year groups, which permitted clearer focus on the most relevant content, allowed space to ask questions, and enabled discussion of how to integrate content into lessons. Teachers had varying levels of availability and commitment, and several attended two further whole-day CPD courses run by the author and a further 1-hour session delivered to all teaching staff. In summary, almost all teachers have been involved in CPD or discussion for 4-6 hours, and some for considerably more.

The relationship between Patience Holt and the author is clearly reciprocal, and much of my data comes from semi-structured interviews, which permitted expansion of the questionnaire topics, and classroom observations of staff, which allowed teachers to discuss and reflect on their teaching. "All is data" (Glaser 2001: 145), and I also make use of informal conversations with school leaders, teachers, trainees and support staff. 
Glaser's 'all' includes the author, who has interacted with the participants, sometimes altering their actions, and thus become part of the data. Given that the researcher also led the CPD sessions, there was a danger that staff may not have felt free to discuss negative perspectives of grammar teaching. It was important therefore from the outset to establish a trusting relationship with staff through "prolonged engagement" and "persistent observation" (Guba and Lincoln 1985). Much of the time I spent at Patience Holt (around 110 hours in total) was spent in conversation with individuals or small year-group sessions with 2-3 staff, where discussion was freer and wide-ranging; I will show later that this included expression of personal weakness and doubt. This study has features in common with ethnographic research, in that it seeks to obtain a holistic view from within, yet it also makes use of discrete-point tests and questionnaires. This use of quantitative and qualitative data from multiple sources, as well as the extent of the researcher's involvement with the school over time, ensures a degree of trustworthiness. Van Lier points out that case studies are sometimes regarded as "a soft and weak approach..." (2005: 195), and they can provide "a surfeit of subjectively compelling explanations" (Campbell 1975, cited in Flyvbjerg 2006: 235), yet it is still possible to draw conclusions which are relevant to the wider educational community.

\section{Ethics}

Staff were given a written summary of the aims of the study and the purposes to which the data would be put, and informed consent was obtained. Participants were able to withdraw from the study at any time. All identities have been protected.

\section{Staff background in languages and grammar}

A large proportion of staff (just under half of TS and more than two thirds of TSS) are bilingual. This reflects both the bilingualism of many children at the school, which can be a strength in acquiring literacy (Gregory et al. 2004), but also the languages of the children. One TS and 10 TSS report having English as a second or third language. The most common L1 is English (18 TS, 11 TSS); the most common L2 is Gujarati (1 TS, 7 TSS); of the eleven languages used or known by staff, the most common are French, Urdu and Punjabi.

Although "[f]or several decades up to about 2000, most state schools in England taught little or no grammar" (Hudson and Walmsley 2005: 2), almost all staff report 
having studied English grammar at primary school, and free comments suggest that staff were indeed reporting some type of formal study of grammar. It is difficult to interpret one teacher's comment that she could now "only recall what I use from day to day," or the claim from another that he studied "only at a very basic level" as referring to the acquisition of literacy rather than grammar per se. In addition, many staff (>60\% of TSS, $>40 \%$ of TS) had studied grammar in an L2, and some have extensive experience: six TSS have studied grammar in more than one L2. Some staff have studied grammar in a language which they do not claim as a working L2. Only 10 staff had not studied an L2 grammar and were also unable to use an L2 to some extent, although it is noteworthy that eight of these were TS.

Viewed together, these data suggest a wide and varied experience of bilingualism and grammar study amongst staff, which is a useful starting point, since bilingualism correlates with more knowledge about language, and this may feed into staff's interpretations of curriculum requirements and their perspectives on children's learning.

\section{Beliefs}

Staff reacted to seven statements on a 5-point Likert-type scale (strongly agree to strongly disagree). Statements B14-17 below were based on positions outlined in NC2014, B18-19 reflect Patience Holt's high proportion of EAL children, and B20 was intended to evaluate teachers' view of their level of knowledge.

- B14 Explicit knowledge of grammar gives primary pupils more conscious control and choice in their language.

- B15 Explicit knowledge of grammar is best taught through a focus on grammar within the teaching of reading, writing and speaking (i.e. grammar should be integrated).

- B16 Explicit knowledge of grammar can be effectively taught in stand-alone lessons (i.e. grammar does not need to be integrated).

- B17 Explicit knowledge of grammar is essential in enabling primary school children to develop full control of language.

- B18 Children who speak another language at home, or who have English as a second language, will benefit from having explicit knowledge of grammar. 
- B19 Children who speak another language at home, or who have English as a second language, will find it more difficult to learn explicit grammar concepts than other children.

- B20 Most primary school teachers teaching explicit knowledge of grammar do not have sufficient knowledge in this area.

Table 1 shows the percentage of staff responding in each category, with the most common response shaded grey. The final column for each group ( $S+S A)$ combines 'agree' and 'strongly agree' responses.

\section{${ }^{* * *}$ Insert Table 1 about here ${ }^{* * *}$}

Table 1 suggests the standard 5-point Likert scale was appropriate. TS' most frequent response is 'neither' for only one question (two for TSS), suggesting little central tendency bias.

Both groups largely agree with NC2014 that KAG improves "control and choice" and is "essential in...develop[ing] full control of language." There is also a high level of agreement that integration is essential in developing this knowledge. However, B15 and B16 present opposing views of this topic, and while the combined agreement rate for B15 (pro-integration) is $\geq 90 \%$ in both groups, for B16 (stand-alone teaching can also be beneficial) responses were more distributed. In other words, substantial minorities in both groups thought there might be a place for decontextualized teaching of KAG. Of course, the two need not be mutually exclusive - it may well be true that integrated teaching is essential and that decontextualized teaching is also useful.

While the majority of staff from both groups agreed that KAG benefited EAL children, B19 elicited more widely distributed responses with the most frequent response indicating lack of certainty. The greatest number of TS and TSS were undecided about whether EAL children would find this type of knowledge more difficult than non-EAL children, which is interesting given that most children either use heritage languages or have English as an L2. Also interesting is that TSS - whom one might expect to have greater insight - were just as ambivalent on this issue as English-L1 TS.

Finally, TS largely agreed that they (that is, the teachers) did not have adequate subject knowledge. $71 \%$ of TSS gave a 'neither' response, which may indicate unwillingness to comment on TS' knowledge. 


\section{Confidence}

Staff reported their confidence in "general understanding" of a set of grammar terms on a five-point scale from 'very weak' to 'very strong'. Most terms were from the NC2014 Glossary, but also included were names of three verb forms (e.g. past perfect continuous) to assess knowledge of the type of grammatical description more common to EAL or EFL training. To reduce time spent on this, terms were grouped where possible. Table 2 shows the terms and the percentage of staff self-evaluating at each level of confidence; the final column for each group ( $\mathrm{S}+\mathrm{VS})$ combines 'strong' and 'very strong' responses. The most frequent response (the mode) is highlighted.

\section{${ }^{* * *}$ Insert Table 2about here ${ }^{* * *}$}

For both TS and TSS the most common self-assessment is 'weak' or 'neither strong nor weak.' The only exception to this is the first group (perhaps the most frequently seen grammar terms), for which staff reported high levels of confidence. For all other terms, reported confidence is low; even for TS, for only two groups of terms do the combined S+VS scores exceed the mode. TSS report lower confidence for almost all terms, with 'total confidence' scores (the sum of the S+VS columns) of 301 for TS and 181 for TSS out of a possible 950 and 1050 respectively. Overall confidence is therefore approximately $30 \%$ (TS) and $20 \%$ (TSS).

There are clearly weaknesses with this data: staff may have preferred to under-report confidence before the audit, and may have hedged their bets (the most common response was 'neither' for 6/10 groups amongst TS and 5/10 groups amongst TSS); and the terms are grouped so we cannot unpick which terms caused particular problems. But the overall point remains that for most groups of terms, most staff appear to lack confidence in their knowledge.

\section{Staff knowledge of terminology}

Knowledge of grammatical terms was audited separately using a pen-and-paper test of the same 30 terms. This was intended to give an overview of staff knowledge which would form the basis of training. Some questions were multiple choice (authentic text provided context for these), and some required staff to produce short answers or identify examples. Examples of test items are below: 
- Embark on a voyage of culinary rediscovery with celebrated American chef Alice Waters.

$\begin{array}{lll}\square \text { adjective } & \square \text { adverb } \quad \square \text { article } \quad \square \text { conjunction } \\ \square \text { noun } & \square \text { pronoun } \quad \square \text { preposition } \quad \square \text { verb } \quad \square \text { I don't know }\end{array}$

- Write a short sentence containing a verb in the passive form.

- Underline any subordinate clauses in the passage below.

The proper price of good food should include the cost of the labour of the people who produce it, not just those who sell it.

Of TS, $3(18 \%)$ scored $<25 \%$ overall, 7 (41\%) scored $26-50 \%, 6(35 \%)$ scored 51 $75 \%$, and $1(5 \%)$ scored $>75 \%$. 17 TSS $(77 \%)$ scored less than $25 \%$, and only $2(10 \%)$ more than $50 \%$. The highest overall score in both groups was $77 \%$.

Table 3 shows the terms and the number of staff who answered correctly. 'Don't know' replies and unanswered questions were treated as incorrect. In addition, each term was tested twice, and to minimise the effect of guessing, both responses had to be correct to gain a point. In 'NC status', C means the term must be taught to children, followed by year group; terms labelled $\mathrm{G}$ are in the Glossary but need not be taught; terms labelled $X$ are not in the Glossary.

\section{${ }^{* * *}$ Insert Table 3 about here ${ }^{* * *}$}

Amongst TS, the most reliably known terms were noun, verb (as word class), adjective, preposition, subordinating conjunction, possessive pronoun, verb and adverbial (as clause elements), subordinate clause and present participle: more than half TS were able to correctly identify them. Almost half correctly identified conjunction, determiner, pronoun, coordinating conjunction and present continuous verb forms. TSS' scores are lower: no terms were known by more than half the respondents. Of terms specified to be taught to children, particularly poorly known amongst TS were modal verb (one correct answer), relative pronoun (two), and passive (five ).

The data in Table 3 is rather rough and ready: because staff who correctly answered only one of each pair scored zero, the results almost certainly underestimate knowledge. However, the scores are an approximate indication of where matters stood and were sufficient for the purposes of designing the training sessions. I consider the wider implications of the knowledge audit in the discussion below. 


\section{Interview, discussion and training data}

I have reported the results of pen-and-paper surveys of grammatical knowledge, confidence and attitudes amongst staff. I now turn to data collected over nine months which makes use of conversations, questions and comments in CPD and planning sessions, post-observation discussions and email queries, as well as interviews. This data is less comprehensive, but more subtle, rich and complex. Much of it was recorded then transcribed and coded thematically using an approach derived from grounded theory (Glaser and Strauss 1967), which despite criticism (e.g. Thomas and James 2006) remains a valuable and widely-used analytical approach. Where audio recording was not possible, I have relied on field notes. This section uses data from three SLT staff who also teach, as well as classroom teachers.

Mark, the member of SLT leading English commented that "staff were very nervous about teaching grammar, and I was very nervous about leading it because [so] few teachers had been taught it". This was sometimes confirmed by teaching staff: one first reaction to the CPD was "I thought I'm going to be found out here!" [Jan]. But the overall picture is more complicated. It is important to distinguish confidence-inknowledge from knowledge itself, and some comments suggest both more of the former than the SLT appear to have allowed for and a willingness to learn:

When I did [the knowledge audit], I thought, yeah, I'm good at spelling and grammar. But there were several [terms] l'd not seen and didn't know, and so the first thing I thought was right, I've got to get better. I went out and got that book...straight away because I thought I need to make sure I'm on it. (Katie)

Several teachers also admitted to struggling with the content of NC2014 and their classroom performance, despite attempts at self-education. And while there was agreement that the CPD had helped, there was also acknowledgement of ongoing weaknesses in content knowledge.

I remember last year...thinking Oh god, I need to teach to this test. And I [Googled] all the terms we had to cover...to teach myself what they meant. But obviously it was new to me and I was going off whatever I thought. This year I feel...really confident. There was so much stuff I didn't know. I am definitely more confident in this grammar stuff. There's stuff I don't know - subject, object... Passive and active does my head in. (Elaine) 
Amongst KS1 teachers, confidence appeared to be lower. Siân (Y2) described the content as "quite challenging" and added that "if I was asked to teach [KS2] l'd be petrified". Her year group colleague Rosie admitted "occasionally l've not got a clue what I'm talking about [in class]".

Many comments suggested conceptual overlap between performative knowledge (the ability to do language, to make it 'correct') and declarative knowledge of terminology and concepts (KAG). One teacher saw KAG as a way of improving her own writing:

Because of [dyslexia] I've struggled with English in the past... Honestly, I wish I had been taught it a long time ago. I would probably have a better understanding, or I wouldn't have the issues that I have had in the past, where I've struggled to write academically, to understand the structure of the writing l've been doing. (Gail)

This implies agreement with the NC2014 position that knowledge improves performance. What is interesting is not only whether this is directly true (and much research so far suggests not), but the extent to which KAG and, more widely, KAL may simply raise awareness. Some comments suggest a movement in this direction:

[Studying grammar] does raise the bar. The fact that I have to know more, well, I should know more. And the majority of teachers... would like to know if they're writing something wrongly. (Jan)

A key claim of the new curriculum is that "[e]xplicit knowledge of grammar...gives us more conscious control and choice in our language" (DfE 2014: 66), and there is evidence (e.g. Myhill et al. 2012) that some types of grammar instruction can improve writing, and teachers showed strong agreement with this when the issue was presented in a survey. But interviews reveal a more ambiguous view. Only one teacher was explicit that "[grammar teaching] is clearly having an impact [and] there seems to be a clear correlation between SPaG and [improved] writing" (Jan). However, it is not clear if she sees (or if there is) causality:

The children who've done really well [in the writing assessment] have better spelling, punctuation and grammar, and those are key components to getting a good level. You can write the most amazing writing ever with brilliant vocabulary but if you can't put a full stop in the right place you can't go above a level 2. (Jan) 
Siân succinctly describes the difficulty of knowing if KAG instruction improves writing:

I think sometimes if you know what an adjective is, what a conjunction is, you can make your writing better... Oh, I could put some describing words in. I could use some adjectives. That would make it better, wouldn't it? But whether [KAG] actually does [improve writing], I don't know.

This highlights a crucial conundrum: even if using (in this case) a wider variety of descriptive words sometimes improves writing, how does knowing the term 'conjunction' help?

Whether or not we take at face value NC2014 assertions about the power of KAG to improve children's writing, and whether a more nuanced view develops of what role KAG can play in raising language awareness, some comments reveal prescriptivist views:

Even though we've taught them that you use the present tense and you use the article, and that cinema is singular, not plural...they still say "I bees ${ }^{1}$ going to cinemas." (Marie)

Such views may reflect the fact that a key task for primary schools is to ensure children become literate in Standard English. NC2014 has fewer overtly prescriptive views than some earlier documents (Cajkler 2004), but the looming presence of the SPaG test make it hard to avoid a focus on 'correct' ways to speak and write. Prescriptive views may also indicate confusion over the purpose of KAG: is the aim to develop confidence and offer children "control and choice" (DfE: 64) in language use, or to improve their written accuracy?

Towards the end of the year, many teachers expressed confidence that grammar teaching was beneficial. Mark sums up the most frequently mentioned case: "the terminology enables you to...give them more effective, more constructive feedback on what [children's] next steps are, and how they can improve." Elaine provided a useful example:

He'd just have a subordinate clause, full stop... I remember sitting down with him quite a few times going through a complex sentence, and I was able to

\footnotetext{
1 'bees' is a local form of to be used irrespective of tense and person
} 
articulate to him where he's going wrong. And we went through subordinate clause, main clause, and I was able to say here's a sentence, show me the subordinate, show me the main. Now show me your sentence. Where does it fit? And I vividly remember it because it was the only way I could get through to him. Whereas before [I could use this terminology] my favourite line was probably it doesn't make sense, it doesn't read right. And they'd say what do you mean? And what do I mean?

This illustrates well the difficulties caused by lack of metalanguage, and crucially, for both teacher and child, shows how developing control of metalanguage can help crystallise nascent insights into how language works and our understanding of it.

Overall, negative comments about KAG were rare. The fear that 'grammar' somehow conflicts with spontaneity has been repeatedly observed (e.g. Watson 2012), yet this was alluded to only once:

If you [say] this is the name for that, it becomes very formulaic. Spontaneity, the inspirational nature of English...could be stifled and affected. It's right, l've got to put this in. As soon as you start putting big words into things, explaining what something is, my fear is that some children will be too focused on the big word, and what they were getting right off the cuff may suffer. (Gail)

Seen closer up, this comment appears a reflection both on children's potential reactions and on how KAL may set the agenda for the teacher. Other teachers did mention children over-using a particular linguistic feature - "Sometimes you do get [children] writing 'the big fat warty slimy green frog' and you go 'well, would you say that normally?"' (Jan) - but some explained this as children "trying to please you - we did ask them to do it" (Katie).

And in contrast to the 'cold grammar' view, most teachers had a largely positive perspective, and some expressed genuine enthusiasm (Katie: "I like grammar, I do like grammar!"). Elaine describes similar enthusiasm, and her comments illustrate how knowledge may interact with performance in complex ways:

As an adult...over the years l've learned to write. Now when I'm writing l'm thinking straight away... All these terms come in my mind, I'm thinking oh yeah, I do these complex sentences. I didn't know they were called complex sentences. I had none of this terminology, none of it. Yeah! I love it. There's a 
real, like, yeah, I know what I'm talking about! Yeah! Power! And it's good to know if you're using it correctly. I spot mistakes all the time now.

This enthusiasm can clearly be passed to children. Jan's comment is instructive and revealing:

They love [grammar]. And I think it's down to the teacher's enthusiasm - and I am enthusiastic about it. A little girl said to me the other day this is a present continuous, and I said is it? I'll be honest, I had to look it up. She said I looked it up, and she must have learned it that way... I will stop a lesson if there's a particularly good sentence. Stop! Listen to this, listen to this! You big it up, and the pleasure the children get from that is just remarkable. Then, once you've grabbed them they will start producing really good sentences.

Of course, passion and intensity can fire enthusiasm in any subject, but this type of comment is an informative contrast to the idea that teachers find grammar inherently uninteresting (cf. comments by 'Grace' cited in Watson 2015: 9-10). Jan makes an intuitive but unexamined leap from children being 'grabbed' to their producing similarly good writing.

Importantly in a school with large numbers of EAL children, there is widespread awareness among staff that the children's diverse linguistic base can be both strength and weakness. This also reveals the complexity of teachers' beliefs; one teacher with fairly prescriptive ideas about rightness is simultaneously aware of the rich territory offered to learning by getting it wrong - Marie pointed out that bilingual children have "a propensity to learn about language quite easily [and] are a lot more open to learning...because they're less scared of making mistakes." Similarly, Elaine makes the point that

[i]t is hard, especially with tenses, plurals, singular, because the parents are also using them wrong. But that's not necessarily [because of] $E A L$, that's also...the backgrounds. Working class... There's a lot of questions, with EAL definitely being one of them.

\section{Conclusions}

This impressionistic study of one school reveals considerable change as the first year of SPaG teaching unfolded. My overall sense at the start was that teaching staff doubted their grasp of the newly-required terminology and their ability to teach it. In 
addition, while there was apparent consistency in staff beliefs about the value and purpose of grammar knowledge, this was not always supported by comments made in informal conversation. The efforts of the SLT to provide opportunities to develop subject knowledge have undoubtedly had some success, but the main agents of change have been the staff themselves. A primary school is an ecosystem, and the beliefs and attitudes of its staff towards any aspect of its professional practice is a part of that system which itself exhibits systematic properties. It may be useful to see this in terms of a dynamic system (Larsen-Freeman and Cameron 2008); although the teachers at Patience Holt may be alone (in one sense) in the class, they frequently train, learn, discuss and plan together, and in their interactions form a new sense of possibility and purpose.

Rather than discuss the extent to which staff's beliefs have been mirrored in practice, my purpose has been to examine those beliefs and ideas in flux as they respond to contextual change and the practical requirements imposed by curriculum change. It has also been important to highlight the complexity of teachers' beliefs about learning and teaching terminology, and the different ways in which KAG can be obtained and maintained. Many important issues remain but it seems to me that the most crucial for teachers and children is this: assuming that KAL and KAG are important and useful and whether they have immediate impact on writing attainment or not - what learning environments are most conducive to developing them? In schools like Patience Holt, staff and children could benefit from exploiting the diverse linguistic knowledge base, yet it seems little use is made of this. This may be a reaction to the relatively narrow confines of NC2014, which despite moving away from the prescriptivism of earlier years still makes it clear that the aim of KAG is to improve writing; it provides little sense of exploration, of pleasure in knowing for its own sake. Yet the enthusiasm of teachers and children for the subject suggests that as understanding deepens there is scope for real change. In many respects, Patience Holt is similar to other schools around Britain, but in the exact permutation of contextual and other factors it is, like other schools, unique.

There is much to explore in this area, and further work might usefully address the ways in which primary teacher attitudes to grammar and KAG change over time; how we might assess teachers' knowledge of grammatical terms and concepts in a reliable, 
standardised way; and the ways in which children themselves perceive this element of their education.

\section{Notes}

${ }^{1}$ A pseudonym: Patience Holt (?-1756) was married to William Arkwright, inventor of the spinning jenny.

\section{References}

1. Australian Curriculum Assessment and Reporting Authority (2012) The Australian Curriculum: English. Version 3.0. Sydney: Australian Curriculum Assessment and Reporting Authority. Retrieved from www.acara.edu.au.

2. Bell, H. (2015) 'The Dead Butler revisited: grammatical accuracy and clarity in the English primary curriculum 2013-2014', Language and Education. 29 (2), 140-152.

3. Bibby, T. (2002) 'Shame: An emotional response to doing mathematics as an adult and a teacher', British Educational Research Journal. 28 (5), 705-721.

4. Borg, S. (2003) 'Teacher cognition in grammar teaching: A literature review', Language Awareness. 12 (2), 96-108.

5. Cajkler, W. (2004) 'How a dead butler was killed: The way English national strategies maim grammatical parts', Language and Education 18 (1), 1-16.

6. Clark, U. (2010) 'Grammar in the curriculum for English: What next?', Changing English. 17 (2) 189-200.

7. Crystal, D. (2006) The fight for English: How language pundits ate, shot and left. Oxford: Oxford University Press.

8. DfE (2014) The National Curriculum framework document 2014. London: DfE.

9. Flyvbjerg, B. (2006) 'Five misunderstandings about case-study research', Qualitative Inquiry. 12 (2), 219-245.

10. Glaser, B. (2001) The grounded theory perspective: conceptualization contrasted with description California: Sociology Press.

11. Gregory, E., S. Long and D. Volk (eds.) (2004) Many pathways to literacy: Young children learning with siblings, grandparents, peers and communities. London: Routledge.

12. Jeurissen, M. (2012) '“Perhaps I didn't really have as good a knowledge as I thought I had." What do primary school teachers know and believe about grammar 
and grammar teaching?', Australian Journal of Language and Literacy. 35 (3), 301316.

13. Jones, P. and H. Chen (2012) 'Teachers' knowledge about language: issues of pedagogy and expertise', Australian Journal of Language and Literacy. 35 (1), 147168.

14. Larsen-Freeman, D. and L. Cameron (2008) 'Research methodology on language development from a complex systems perspective', The Modern Language Journal. 92 (2), 200-213.

15. Leach, J., J. Williams and R. Andrews (2002) 'Introduction: Research in subject knowledge and application', British Educational Research Journal. 28 (5), 643-648.

16. Lincoln, Y. \& E. Guba (1985). Naturalistic inquiry. Newbury Park: Sage.

17. Ministry of Education (2007) The New Zealand curriculum. Wellington: Learning Media.

18. Myhill, D., S. Jones, H. Lines and A. Watson (2012) 'Re-thinking grammar: The impact of embedded grammar teaching on students' writing and students' metalinguistic understanding', Research Papers in Education. 27 (2), 139-166.

19. Myhill, D., S. Watson and A. Watson (2013) 'Grammar matters: How teachers' grammatical knowledge impacts on the teaching of writing', Teaching and Teacher Education. 36, 77-91.

20.Phipps, S. and S. Borg (2009) 'Exploring tensions between teachers' grammar teaching beliefs and practices', System. 37, 380-390.

21. QCA (1998) The Grammar Papers. London: QCA.

22. Reedy, D. and E. Bearne (2013) Teaching grammar effectively in primary schools. London: UKLA

23. Sangster, P., C. Anderson, P. O'Hara (2013) 'Perceived and actual levels of knowledge about language amongst primary and secondary student teachers: Do they know what they think they know?', Language Awareness. 22 (4), 293-319.

24. Sealey, A. (1999) 'Teaching primary school children about the English language: A critique of current policy documents', Language Awareness. 8 (2), 84-97.

25. STFA (2015) 2016 key stage 1 English grammar, punctuation and spelling: sample test materials, mark scheme and test administration instructions, https://www.gov.uk/government/publications/2016-key-stage-1-english-grammarpunctuation-and-spelling-sample-test-materials-mark-scheme-and-testadministration-instructions (accessed 23.9.15) 
26. Thomas, G. and D. James. (2006) 'Reinventing grounded theory: Some questions about theory, ground and discovery, British Educational Research Journal. 32 (6), 767-795.

27. van Lier, L. 'Case study' in E. Hinkel (ed) (2005) Handbook of Research in Second Language Teaching and Learning. New York: Laurence Erlbaum.

28. Watson, A. (2012) 'Navigating 'the pit of doom': Affective responses to teaching grammar', English in Education. 46 (1), 22-37.

29. Watson, A. (2015) 'Conceptualisations of grammar teaching: L1 English teachers' beliefs about teaching grammar for writing', Language Awareness. 24 (1), 1-14.

30. Waugh, D., C. Warner and R. Waugh (2013) Teaching grammar, punctuation and spelling in primary schools. London: Sage.

31. Williamson, J. and F. Hardman (1995) 'Time for re-filling the bath?: A study of primary student-teachers' grammatical knowledge', Language and Education. 9 (2), 117-134. 